\title{
Phrasing and Relative Clauses in Chimwiini ${ }^{1}$
}

\author{
Charles W. Kisseberth
}

Tel Aviv University

\begin{abstract}
We focus in this paper on two prosodic phenomena in Chimwiini: vowel length and accent (or High tone). Vowel length is determined in part by a lexical distinction between long and short vowels, and also by various morphophonemic processes that derive long vowels. Accent is penult in the default case, but final under certain morphosyntactic conditions. In order to account for the distribution of vowel length and the location of accents in a Chimwiini sentence, it is necessary to segment sentences into a sequence of phonological phrases. This paper examines the phonological phrasing of both canonical relative clauses and what we refer to as "pseudo-relative" clauses. An account of relative clause phrasing is of critical importance in Chimwiini due to the extensive use of pseudo-relatives in the language. Close examination of the pseudo-relatives reveals that their phrasing is not exactly the same as the phrasing of canonical relative clauses.
\end{abstract}

\section{Introduction}

In this paper we initiate an exploration of the phonological phrasing of relative clauses in Chimwiini, a Bantu language closely related to Kiswahili but differing from it in significant ways, particularly in regards to prosody (the central topic of this paper). By "phonological phrasing," we refer to the fact that in order to successfully account for the prosodic pattern of a Chimwiini sentence, the sentence must be exhaustively parsed into a sequence of segments which we label phonological phrases. Although most sentences do not have a unique phrasing, the possible phrasings of any given sentence is highly restricted.

1 The research in this paper was funded by the National Endowment for the Humanities, grant \#DEL PD-50009 ("Documentation of Chimwiini," principal investigator: Prof. Brent Henderson) as part of their program "Documenting Endangered Languages". My thanks both to the NEH and to Brent Henderson. 
Research into the possible phrasings of a Chimwiini sentence aims at (a) finding the principles that separate possible from impossible phrasings and (b) determining what factors lead to one phrasing versus another.

There are two prosodic phenomena whose description demands a sentence be segmented into a series of phonological phrases. One of these phenomena is accent (characterized by high pitch). Chimwiini has an accentual contrast between penultimate (second syllable from end) and ultimate (final syllable). This accentual contrast is dependent mostly on morphosyntactic considerations, but what is crucial for the concerns of the present paper is that it is a phrasal rather than a word-level phenomenon. Kiswahili lacks this accentual contrast entirely. The second prosodic phenomenon is vowel length. Chimwiini contrasts short and long vowels in underlying representation (unlike Kiswahili), and it has various morphophonemic processes that create long vowels. However, long vowels are restricted in terms of where they may appear. Roughly, they may appear only in the penult or the antepenult syllable. But once again it is not the word, but rather the phrase that determines whether a syllable is penult or antepenult.

In this paper, we examine two principal types of relative clauses: "canonical" relative clauses and "pseudo"-relative clauses. Canonical relative clauses involve a head that is modified by a relative clause, although this head may be absent in the surface structure. The relative verb is not the main verb of the sentence. Pseudo-relatives, on the other hand, do not modify a head. Whether the pseudo-relative verb is the main verb of the sentence is not always clear. In some cases, there is an overt copular verb $\boldsymbol{n i}$ which might be taken to be the main verb of the sentence. These cases of pseudo-relativization might be regarded as "cleft" sentences. But the copular $\boldsymbol{n i}$ can be omitted and in some cases may not even be allowed. In these cases where the copular is absent or impossible, the pseudo-relative verb may be regarded as the main verb in the sentence. There is a third sort of relative clause structure in Chimwiini, adverbial relative clauses, which we do not discuss due to space limitations.

\section{Essentials of Chimwiini Prosody}

This paper assumes broad familiarity with the prosody of Chimwiini (cf. Kisseberth and Abasheikh 1974, 2004; Kisseberth 2005, 2010). We will restrict ourselves to a summary of the most critical points in this section.

\subsection{Accent}

At the (prosodic) word level, each word bears an accent. In the default case, accent is on the penult (if there is a penult, otherwise on the only syllable). 
Under specific morphosyntactic conditions, accent is final. The accented syllable may also be referred to as the H-toned syllable, since its only consistent phonetic marking is a pitch level that is higher than the preceding syllable (though in ordinary connected speech the pitch may rise on the pre-accent syllable and sometimes the pitch may even be flat over these two syllables). The accented syllable may be emphasized, in which case its pitch is higher but there are doubtless additional phonetic cues.

Default penult accent is illustrated in (1). The acute sign indicates the accent.

\section{(1) nouns and infinitives}

$\begin{array}{lll}\text { [maskíini] 'poor person' } & {[\text { [m-láango }]} & \text { 'door' } \\ \text { [safári] 'trip' } & \text { 'tr-saafíri] } & \text { 'traveler' } \\ \text { [k-oowéla] 'to swim’ } & {[\text { kú-fa }]} & \text { 'to die' }\end{array}$

\section{certain finite verb forms}

[sh-ta-x-píka] 'we will cook' [wa-ta-ku-bigána] 'they will beat each other'

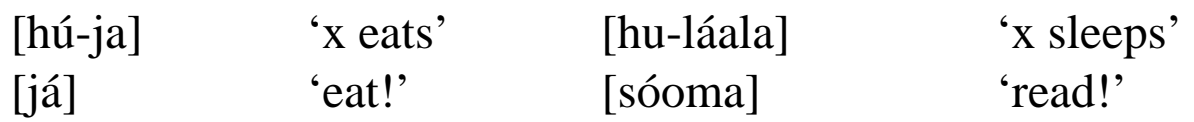

Two cases of final accent are illustrated in (2). First or second person subject forms in the present and past tenses trigger final accent, and all relative verb forms (regardless of their subject marking or verb tense) trigger final accent.

(2) person-marking final accent: first/second person, present or past tenses [n-jiilé] 'I ate' [jiilé] 'you (sg.) ate'

cf. [jíile] '(s)he ate'

[n-someelé] 'I read' [someelé] 'you read'

cf. [soméele] '(s)he read'

[n-na-k-aandiká] 'I am writing' [na-k-aandiká] 'you are writing' cf. [wa-na-k-aandíka] 'they are writing'

[n-na-x-pakulilá] 'I am dishing out with'

[na-x-pakulilá] 'you are dishing out with'

cf. [wa-na-x-pakulíla] 'they are dishing out with' 
relative-clauses marked by final accent

[jiiló] 'the one who ate'

[mw-ana nth-a-k-aandiká] 'the boy who did not write'

[chi-buku ch-uziizá/ n-chha Núuru]

'the book that was sold/ belongs to Nuuru'

At the sentence level, some prosodic words are accented and some are not. It turns out, that the generalization that explains this is the following: sentences are exhaustively parsed into a series of phrases, and the last prosodic word in the phrase bears an accent and no other word does. Again, the default accent is penult, but under specific morphosyntactic conditions, the accent is final. The sentences in (3) illustrate some typical phrasings in Chimwiini.

(3) a VP consisting of just a Verb bears accent; a subject NP consisting of just a Noun bears accent

[hóosi/ i-chi-gúura] 'if the shade/ moves'

[hokómu/ i-tindishíle] 'a verdict/ has been given'

[mw-áana/ oloshéle] 'the boy went'

a verb does not bear accent when it is followed by a complement, rather the last word of the complement bears the accent

[n-jilee namá] 'I ate meat', [jilee namá] 'you ate meat'

vs.

[jilee náma] '(s)he ate meat’, [wa-jilee náma] 'they ate meat’

[n-uzile chi-buku ch-a Hamadí] 'I bought Hamadi’s book'

vs.

[uzile chi-buku ch-a Hamádi] 'he bought Hamadi’s book'

[n-inenzele xaribu y-aa wowí] 'I walked near the river'

vs.

[inenzele xaribu y-aa wówi] 'he walked near the river'

[chi-mera n-dilaa n-khúlu/ y-a múu-yi]

'he looked for the main street/ of the town'

a NP bears an accent on the final word in the NP

[ni-m-pele Jaamá/ chi-buukú] 'I gave Jaama/ a book'

[ni-m-pele Jaamá/ zi-buku s-tatú] 'I gave Jaama/ three books'

[ni-wa-pele w-aaná/ zi-luti s-tatu zi-lee zi-lé]

'I gave the children/ the three long sticks'

[Núuru/ pele madrása/ péesa] 'Nuuru/ gave the school/ money' 
[wé/ na-ku-biga boolí/ mali y-a waa-nthú]

'you/ are looting/ people's wealth [lit. wealth of people]'

It will be noticed that the phrase containing an element that triggers final accent has final accent, while in the absence of a final-accent trigger the accent is penult. However, the situation is a bit more complicated. For instance, if the trigger is the verb, then (in the default case) final accent occurs not just on the phrase containing the verb but also on each phrase in the verb phrase: [ni-mpele Jaamá/ chi-buukú]. We give an account of this in Kisseberth (2010), where it is suggested that phrasing may be recursive in Chimwiini and that both complements in the example above are included inside a larger phrase that enfolds the entire verb phrase. In this paper, we do not indicate this proposed larger phrasing.

There are additional complexities in connection with the appearance of final accent in phrases and we shall look at some of these in the course of this paper. But the preceding summary of accent is sufficient for the introductory purposes of this section. Let us turn next to a rather more complex prosodic phenomenon: vowel length.

\subsection{Vowel length}

Chimwiini contrasts short and long vowels. Long vowels may be underlying or derived by morphophonemic principles. We indicate a long vowel by doubling the vowel symbol.

\section{(4) underlying long vowels}

[x-kúula] 'to extract'

[sóomu] 'fasting'

cf. [x-kúla] 'to grow'

[sómo] 'namesake'

\section{derived long vowels}

/ku+ala/: [k-áala] 'to plant' /ku+iwa/: [k-íiwa] 'to know'

[ku+uluka/: [k-uulúka] 'to fly’ /ku-eleza/: [k-eeléza] 'to explain’

When we look at words in isolation, it is immediately clear that long vowels are restricted in the environments in which they may occur. They may appear in either the penult or the antepenult syllable, but not both at the same time (except in a restricted set of borrowed words): 
(5) penult long:

[x-shíinda] 'to defeat', [x-sóoma] 'to read', [ku-bóola] 'to steal', [máashe] 'blind'

\section{antepenult long:}

[ku-miimína] 'to pour', [x-taambúla] 'to understand', [ku-liingána] 'to be equal'

\section{both penult and antepenult long:}

- absent in native words,

- absent under morpheme concatenation,

- found only in loanwords: [taawúusi] 'peacock', [faanúusi] 'lamp’, [faalúuta] 'a kind of gruel'

An underlying or derived long vowel will shorten if it is in a pre-antepenult syllable or if it is in an antepenult syllable followed by a long penult. Selkirk (1986) accounts for these shortening phenomena by postulating that there is abstract stress that is assigned by the Latin Stress Rule (stress the penult if long, otherwise stress the antepenult). Unstressed vowels must be short. Thus preantepenult syllables, as well as antepenult syllables followed by a long penult, are all unstressed syllables and thus must be short. We shall adopt Selkirk's analysis. (It should be emphasized that the "stress" here referred to is entirely abstract; there is no phonetic characteristic that is a necessary element of a socalled stressed syllable, and furthermore these stressed syllables play no role in the language's intonational system or indeed any other system beyond their role in permitting vowel length.)

Abstract stress is not a word-level matter, but a phrasal matter. The stressed syllable is calculated from the right edge of the phrase. Furthermore, stress is not calculated by looking just as the last prosodic word in the phrase, but rather at the entire phrase. The phrases that are relevant for abstract stress assignment are the same phrases as are relevant for the assignment of accent. Some example sentences:

(6) [sultani w-aa nóka/ chi-m-uza Hasíibu/ xabarí=z-e]

'The king of the snakes/ asked Hasiibu/ his news.'

[ni-wa-wene wa-nthu w-iingí/ wa-na-kuu-yá] 'I saw many people/ coming.' [n-filatililile kuwa Nuurú/ ta-kuu-yá] 'I expected that Nuuru/ would come.'

In the phrase sultani waa noka 'the king of snakes', the noun sultaani has a long penult vowel in its underlying form, but the length must be lost in this phrase since it is not stressed (since no pre-antepenult vowel is stressed). Notice that there is a long vowel in the associative marker waa. This does not represent lexical length, but is a consequence of a principle that requires word-final 
vowels to be long when they occupy a stressed position. We do not discuss this principle in the present paper. In the phrase $\boldsymbol{c h i - m - u z a ~ H a s i i b u , ~ t h e ~ v e r b ~ h a s ~ a n ~}$ input structure /chi-mu-uza/. If the verb were to appear in phrase-final position, the morphophonemic rules would fuse $\boldsymbol{m u} \boldsymbol{u} \boldsymbol{u}$ into a long vowel: chi-m-uиza. However, in the phrase chi-m-uza Hasiibu, this long vowel must shorten because it is in an unstressed syllable. (Remember: the notion of stress here is a completely abstract one. The stressed syllable bears no phonetic characteristic other than it is possible for this syllable to be long, though not necessary.) The other two sentences in (6) also illustrate shortening of unstressed syllables (cf. the isolation forms: $\boldsymbol{n i - w a - w e e n e ́ ~ ' I ~ s a w ~ t h e m ' , ~ w a ́ a - n t h u ~ ' p e o p l e ' , ~} \boldsymbol{n}$-filajtiilé 'I expected').

We have now summarized the two independent sources of evidence for phrasing in Chimwiini: accent and vowel length. Let us now say something about the principles behind the phrasing of Chimwiini sentences.

\subsection{Phrasing: Align-XP Right}

To a large extent, the basic phrasing of a Chimwiini sentence is determined by the Align-XP Right principle first articulated in Selkirk (1986). This principle says that the right edge of a lexical maximal projection must stand at the right edge of a phonological phrase. The most obvious effects of this principle are that

- the subject of a sentence is phrased separately from a following verb;

- a verb is grouped with the first complement, but other complements are phrasally separated;

- pre-verbal XP's are phrasally separated from one another.

As discussed above, two prosodic phenomena are reliant on these phrases. First of all, a long vowel occurs only in the penult or the antepenult syllable of the phrase. Second, each of the phrases defined by Align XP-R bears an accent on the final word of the phrase. If that final word is a monosyllable, then it always bears the accent. If the final word is bisyllabic or longer, it bears penult accent in the default case, but final accent in the presence of a final-accent trigger (e.g. first/second person present or past tense verb, or a relative verb).

Before we illustrate the predictions that Align-XP R makes, we need to say something about the transcriptions that will be used in the remainder of the paper. All example sentences in the rest of this paper will be written with slant marks separating phrases. The beginning of a sentence is the beginning of a phrase and the end of a sentence is the end of a phrase. We write long vowels whenever they occur in pronunciation. With regard to accent, we do not indicate accent when it is entirely predictable; thus we do not indicate the accent on a phrase-final monosyllabic word, since such words are necessarily accented. We 
also do not write an accent mark in the default case, i.e. when it resides on the penult syllable of the last word in the phrase. We only write accent in the marked case, i.e. when it is word-final (in a bisyllabic or longer word). Of course, all words that are not final in the phrase do not bear an accent.

It is crucial that the reader remember that in the rest of this paper, if a phrase does not have an accent mark, then accent is on the only syllable of a phrase-final monosyllabic word and on the penult of a polysyllabic word. There are no phrases that in pronunciation do not have an accented syllable (ignoring some instances where monosyllabic pronouns may be deaccented).

The representation of segments does not require much discussion. There is a contrast between three dental sounds (underlined): $\underline{\boldsymbol{t}} \underline{\boldsymbol{d}} \underline{\boldsymbol{l}}$ and their alevolar counterparts: $\boldsymbol{t} \boldsymbol{d} \boldsymbol{l}$. There is a fairly rare bilabial fricative we write as $\boldsymbol{b}$. The voiced interdental fricative is also written with a strikethrough: $\boldsymbol{t}$. Aspiration, which only occurs on voiceless stops when prenasalized, is indicated by the symbol $\boldsymbol{h}$ after the stop consonant.

Let us cite now examples where Align-XP Right predicts the observed phrasing.

(a) subject phrased separately from verb

sultani uyu/sulille m-loza mw-aanawe/ mu-ke

'This sultan/ wanted to marry his son/ to a woman.'

chi-zeele/chi-m-paa dawa 'The old woman/ gave him medicine.'

(b) verb and first complement are grouped together

m-phete chi-buku ch-a Muusá

w-ote/ wa-sh-pokezanya ku-vula m-aayi

water.'

(c) successive complements are phrasally separated

wa-m-pokeze m-geeni/ mi-zigo=y-e 'They gave to the guest/ his luggage.'

Hamadi/ mw-andikilile mw-aana/xati/ ka Nuuru

'Hamadi/ wrote for the child/ a letter/ to Nuuru.'

(d) successive preverbal XP's are phrasally separated

teena/sku mooyi/ma-sku/mkula=z-e/wa-chi-weka majlísi

'Then/ one day/ at night/ his elder brothers/ held a meeting.'

Abú/sh-koopa/ chi-m-gafiile 'Abu/ alcoholic drink/ missed (getting).'

In (7a) we see that the subject NP sultani uy $\boldsymbol{u}$ is a phrase since $\boldsymbol{u} \boldsymbol{y} \boldsymbol{u}$ is accented on its initial vowel, while sultaani 'king' loses length from its penult syllable and also bears no accent, indicating that it must not be at the end of a phrase. In (7b), we see that the verb, which in isolation would be pronounced $\boldsymbol{m}$-pheeté 'I 
got', must be in the same phrase as its complement since the verb shortens its vowel and lacks any accent. In (7c), we see that the first complement of the verb, $\boldsymbol{m}$-geeni, must be at the end of a phrase since it retains its long vowel and also bears accent. If it formed a phrase with $\boldsymbol{m i - z i g o}=\boldsymbol{y}-\boldsymbol{e}$, then its long vowel would have to shorten since it would be in an unstressed position and $\boldsymbol{m}$-geeni would also lack an accent due to its not being phrase-final. Finally, in (7d), teena must be in a separate phrase from sku mooyi as shown by the fact that it retains its long vowel and bears an accent.

\subsection{Phrasing: Focus}

Although Align-XP Right is the bedrock of phrasing in Chimwiini, there is another consideration that leads to phrases that are smaller than those predicted by Align-XP Right. Specifically, the presence of focus (or more generally, emphasis) on a word leads to that word being at the end of a phrase even if it is not at the end of an XP. (This same phenomenon was observed by Kanerva in his important work on Chichewa; see Kanerva (1990).) Some examples are given in (8).

(8)

(a) emphasized verb separated from its complement

m-taana/sh-faanya/z-aa ye/ amuriilá

'The servant/ did/ what she/ was told.'

chi-lawa/karka muu-yi/ oyo 'He left/ from town/ that.'

(n)-na-x-suulá/ we/ k-enda naami/ ku-ja uki

'I want/ you/ to go with me/ to eat honey.'

(b) emphasized noun separated from a demonstrative modifier

waa-nthu/awo/wa-chi-'i-tukula/sanduuxu/iyo/mpaka/lfuwooni

'People/ those/ carried/ box/ that/ up to/ the shore.' chi-m-pa m-fazi/shilingi xamsiini/izo/ ku-m-fulila sh-kooya.

'She gave a blacksmith/ fifty shillings/ those/ to forge for [e.g. his wife] a necklace.'

sh-funga safari/chi-lawa/ karka muu-yi/ oyo

'He set out on a journey/ and left/ from town/ that.'

In elicitation, it is very common to find phrases that are maximal, with the right edge of the phrase almost always being the right edge of a maximal projection. However, in narratives, it is very common to find smaller phrases, sometimes to the point where nearly every word in the sentence constitutes a phrase (cf. the first example in (8b).

A significant special case of the above phenomenon is negative verbs, which seem to have inherent focus and thus to typically be at the end of a 
phrase. (The literature contains references to other Bantu languages where negative verbs have inherent focus; see, for instance, Hyman (1999).)

(9) marti $\boldsymbol{w}$-iitu/nth-aa-ku-ya/numbaa=ni 'Our guest/ did not go/ home.' mu-kee=w-e/ nth-a-x-shiika/ miimba 'His wife/ did not become/ pregnant.'

There are other factors that affect a sentence's phrasing, but we omit discussion here since they do not bear on the matters discussed in this paper. It is, however, necessary to discuss a major connection between the appearance of final accent and focus. This is the topic of the next section.

\subsection{Final Accent and the Accentual Law of Focus}

The principal topic of this paper requires that we look closely at final accent. As mentioned earlier, final accent is triggered by certain morphosyntactic factors. It was noted earlier, and we will soon see in more detail, relative clause structure is one of these factors. But in this section we will discuss just person-marking final accent.

In a verb phrase where there is no focus on a VP-medial element, first and second person subject forms in the present and past tenses exhibit final accent at the end of each phrase in the VP:

\section{(10) ni-wa-pele w-aaná/maandá ～'I gave the children/bread.' ni-m-bozele mw-aaná/ chi-buukú 'I stole from the child/ a book.'}

In these examples, the logical indirect object occupies the post-verbal position in the default word order and governs the agreement on the verb.

A very important principle determines the scope of final accent in the VP, however. We refer to this principle as the Accentual Law of Focus. What this principle says is that the final accented triggered by first or second person present or past tense verb forms has no effect beyond a focused element in the verb phrase.

It is possible, in examples such as those in (10), to emphasize the indirect object, in which case the final accent appears on it and not on the second complement (i.e. the logical object). In the following examples, we place the symbol " in front of the focused word.
(11) ni-wa-pele "w-aaná/ maanda
'I gave the children/ bread.' ni-m-bozele "mw-aaná/ chi-buuku 'I stole from the child/ a book.'

If focus is on the logical object, that word must occur in post-verbal position, where it will exhibit final accent and the following phrase will not. 

ni-wa-pele "maandá/ w-aana
'I gave bread/ to the children.' ni-m-bozele "chi-buukú/mw-aana
'I stole a book/ from the child.'

There is more that can be said about the pitch pattern here in addition to the matter of the location of accents. In sentences lacking any sort of special focus, the accents in a sentence display a typical downstep pattern: each phrase's accent is lowered relative to the accent in the preceding phrase. However, when there is focus/emphasis present, the pitch on the focused element is raised and does not show the usual downstep. Furthermore, the pitch lowering on the next phrase seems to be more radical than in the normal default downstep pattern. It should be noted that in the absence of a final-accent trigger, all phrases will have default penult accents, but the pitch pattern described here will still obtain. For example, in Muusa/ wa-pele "maanda/ w-aana 'Muusa gave bread/ to the children', maanda has a penult accent that is raised rather than downstepped, and the pitch on the penult syllable of waana is radically lowered in pitch.

To return to the sentences in (12), it is not possible for the final accent to be on both the focused post-verbal NP and the following XP:

\section{(13) *ni-m-bozele "chi-buukú/ mw-aaná}

'I stole a book/ from the child.'

In Chimwiini, (person-marking) final accent does not pass to a phrase following a focused element. Further support for this claim comes from examples where the verb is focused. In that event, the verb will display final accent (if it is a verbal form that triggers final accent) and all the following phrases will have default accent.

\section{(14) "ni-wa-peelé/w-aana/maanda "ni-wa-peelé/maanda/w-aana}

'I gave/ the children/ bread.'

'I gave/ bread/ to the children.'

There is another restriction on the scope of final accent that deserves mention before we turn to the main theme of this paper: the special behavior of time adverbials, which is discussed in the next section.

\subsection{Final Accent and Time Adverbials}

Align-XP Right predicts that a time adverbial phrase will be phrased like any other XP. This is not entirely correct. Although time adverbials are like other XP's in that they are phrasally separated from a preceding XP (and a following $\mathrm{XP}$, though this is not a matter that needs discussion here), they differ in that (in the default case) they are separated phrasally from a preceding verb. The data in (15a) illustrates the expected separation from a preceding XP, while the data in (16) illustrates that a time adverbial also separates from a preceding verb. 
(15)

(a) Muusa/na-ku-jaa nama/isa

'Muusa/ is eating meat/ now.'

ma-poliisi/wa-m-shishile mw-iizi/yana

'police/ caught thief/ yesterday.'

mw-aana/bashize chi-buuku/yuuzi

'the child/ lost book/ day before yesterday.'

(b) n-tha-x-sooma/keesho 'I will study/ tomorrow.'

Haliima/ pishile/ yuuzi 'Haliima/ cooked/ day before yesterday.'

It is likely that the pitch pattern in (15a), if examined closely, would provide some evidence that the time adverbial is distinct from other XP's in the same linear position. Fortunately, there is more obvious evidence. This evidence is provided by the case of verb phrases where there is a final-accent trigger. Look at the data in (16).

(16) we/ pishilé/ yuuzi

'You/ cooked/ day before yesterday.'

ni-m-pele mw-aaná/ chi-buukú/yuuzi

'I gave the child a book the day before yesterday.'

mí/ na-ku-jaa namá/ isa ' $\mathrm{I}$ / am eating meat/ now.'

n-na-x-saafirí / leelo

'I am leaving on a trip/ today.'

n-andishilee xatí/ yana

'I wrote a letter/ yesterday.'

mi/ndazile Miiní/ yana

'I left Brava yesterday.'

waawé/mi/m-bene n-dootó/yana ma-sku

'My father/ I/ saw dreams/ last night.'

In these examples, we see that while ordinarily the final accent triggered by certain verb forms extends to the end of the verb phrase, here the accent stops in front of the time adverbial.

From these data, one could perhaps conclude that the time adverbials are outside the verb phrase. However, if one focuses on the time adverbial, then the time adverbial is brought within the scope of final accent (and furthermore, if it is after the verb, within the same phonological phrase as the verb):

n-na-x-safira "leeló m-phanzilee mu-tí/ "yuuzí n-andishilee xatí/"yaná mi/n-dazile Mwiiní/"yaná nth-a-x-soma "keesho
'I am leaving on a trip today.'

'I climbed a tree/ the day before yesterday.'

'I wrote a letter/ yesterday.'

'I left Brava/ yesterday.'

'I will study tomorrow.' 
The conclusion that we draw is that in the default case, a time adverbial is out of focus, and the scope of final accent always reflects the focus structure of the VP in main clause sentences.

\section{The Phrasing of Relative Clauses}

In this section we turn to the primary theme of the present paper: the phrasing of relative clauses in Chimwiini. Before looking at this matter in detail, it is necessary to make some general observations about relative clauses in Chimwiini.

The relative verb can be identified by two surface characteristics. The first characteristic is that in many tenses, a relative verb ends in the vowel $\boldsymbol{o}$, even though in corresponding non-relative forms the final vowel is $\boldsymbol{a}$ or $\boldsymbol{e}$. The major exceptions to the use of $\boldsymbol{o}$ are in the passive perfect relative (where the final vowel is $\boldsymbol{a}$ ) and in negative tenses. Thus while $\boldsymbol{o}$ occurs frequently in relative constructions, it is not invariably present. The second characteristic of a relative verb is that it triggers final accent. This is an invariable property of a relative verb. There are no exceptions. (This final accent appears at the end of each phonological phrase in the relative verb phrase, but not necessarily on the relative verb itself).

Initially it will be useful to recognize two distinct relative structures. In all relative clause structures in Chimwiini, the head of the relative clause precedes the relative verb. When the head of the relative clause is a NP that also functions as the subject of the relative verb, then we have the overt sequence head-relative verb. We will refer to this as subject relativization. When the head of the relative clause functions inside the relative clause in a non-subject role, we will refer to this as non-subject relativization. In this type of relativization, the head is ordinarily linked to the subject of the relative verb by means of the so-called "associative particle" $\boldsymbol{A G R}$-a , resulting in the following sequence: $\boldsymbol{h e a d}-\boldsymbol{A G R}$ $\boldsymbol{a}$ - subject - relative verb. The AGR element on the associative particle is determined by the noun class of the head.

We will examine the phrasing of subject relatives first.

\subsection{The Phrasing of Subject Relative Clauses}

As indicated above, when the head of a relative clause refers to the subject of the relative verb, it immediately precedes the relative verb. It is not always the case that the head is phrased with the relative verb, but it certainly may be. It is this possibility that differentiates the head in subject relativization from the subject of a non-relative verb. The subject of a non-relative verb can never be grouped together with that verb if it precedes the verb (this, of course, is a consequence of the Align-XP Right principle). 
The following are a few examples where we recorded the head grouped together with the relative verb:

(a) Halima liziló

'the Haliima who cried' (cf. Haliima/ lizile 'Haliima/ cried.')

(b) mu-nthu na-ku-meroowá/ ni uyu

'The person who is being looked for/ is this one.'

(cf. muu-nthu/na-ku-meroowa 'The person/ is being looked for.')

(c) mu-nthu ofeto $x$-fakatál na-x-pumula

'The man who is tired from running/ is resting now.'

(cf. muu-nthu/ofete $\boldsymbol{x}$-fakata 'The man/ is tired from running.')

(d) mw-alimu bozelo chi-buukú/ni Huseeni

'The teacher who stole the book/ is Huseeni.'

(cf. mw-aalimu/bozele chi-buuku 'The teacher/ stole a book.')

In these examples, the heads lack an accent since they are not phrase-final and their long vowels are shortened since these vowels are located in unstressed syllables.

Although the head of the subject relative clause may be grouped phrasally with the relative verb, it is not uncommon to find it being phrasally separated.

(19) ni-m-wene mw-aalimú/bozelo chi-buku ch-a mw-aaná

'I saw the teacher/ who stole the child's book.'

muи-nthu/na-x-suloowá/ ni uyu 'The person/ who is wanted/ is this one.', as well as

mu-nthu na-x-suloowá/ ni uyu

'The person who is wanted/ is this one.'

basi/ mu-ke/ chi-lawa/ masku/ ch-enda wowii=ni/ ku-m-talaa noka / ubleelá

'So/ the woman/ went out/ at night/ (and) went to the river/ to pick up the snake/ that was killed.'

mafta/ ya-lazilo ka namaa=ni/ sh-taala/ chi-ya-tila/ karka zi-balaasi/ saba

'The oil/ that she took from the meat [e.g. of the snake]/ she took/ and put it/ in clay jars/ seven.'

suxuu=ni/ baaba/chi-m-pataa mu-ke/xirilo $x$-kala na mw-aana=we 'At the market/ father/ found a woman/ who agreed to stay with his child.' ni-m-tambiilé/ muu-nthu/x-ambilo jawabu izí/nii dafa

'I recognize that/ the one/ who told you these answers/ is the kite.'

n-thale/ i-laziló/ ha-y-ruudi/chi-nume

'An arrow/ that has left/ does not return/ back.' (A proverb.) 
chi-buuku/ch-uziizá/n-chha Nuuru

'The book/ that was sold/ belongs to Nuuru.'

mw-aana/m-bozelo Nuurú/ chi-buukú

'The child/ who stole from Nuuru/ the book.'

ye/ sulile kumloola/mwanaamke/ lazilo ka ahlí

'He/ wanted to marry/ a girl/ who came from his clan.'

muu-nthu/fanyiizó/ hu-liwala/ fanyiizá/ h-a-liwali.

'The one/ who has done something wrong/ forgets/ (but) the one who has been wronged/ does not forget.' (A proverb.)

We will have something to say about the phrasing of the relative verb and its complements later, but for now we turn to non-subject relatives.

\subsection{The Phrasing of Non-Subject Relative Clauses}

When the head of a relative clause functions as a non-subject in the relative verb phrase, and the verb has an overt pre-verbal subject, there is an $\boldsymbol{A G R}$ - $\boldsymbol{a}$ element linking the head to the relative verb's subject. The overt subject of the relative verb is of course always phrasally separated from the verb, but the head may be separated from the $\boldsymbol{A G R} \boldsymbol{\boldsymbol { a }} \boldsymbol{N P}$ or phrased with it.

(20)

(a) head phrased separately

Nuuru/inenzeeze/gaari/y-a Haaji/uziló

'Nuuru /drove/ the truck/ that Haaji/ bought.'

ni-m-wene mw-aaná/ w-aa mí/ni-m-bozelo chi-buukú

'I saw the child/ who I/ stole a book from'

n-uzize chi-buukú/ch-a Nuuru/m-bozelo mw-aaná

'I sold the book/ that Nuuru/ stole from the child.'

laakini/mw-aana/iize/ ku-m-loola/mw-anaamke/w-a waawa=y-e/

m-sulililiiló

'But/ the boy/ refused/ to marry/ the girl/ that his father/ wanted for him.' 
(b) head phrased with AGR-a NP

chi-su ch-aa mi/n-uuziló 'the knife that I/ bought'

chi-su ch-aa mi/ni-ch-uuzilo' 'the knife that I/ bought (it)'2

n-uzize chi-buku ch-aa mi/ni-m-bozelo mw-aaná

'I sold the book that $\mathrm{I} /$ stole from the child.'

n-uziizé/ chi-buku ch-aa mí/ni-m-bozelo mw-aaná

'I sold / the book that I / stole from the child.'

n-uzize chi-buku ch-a Nuurú/m-bozelo mw-aaná

'I sold the book that Nuuru /stole from the child.'

n-uziizé/ chi-buku ch-aa Nuuru/m-bozelo mw-aaná

'I sold/ the book that Nuuru /stole from the child.'

pesa $z$-aa mi/n-xirile ki-zi-ruudá 'the money that I/ agreed to return [it]'

ni-m-wene mw-ana w-aa mi/ni-m-bozelo chi-buukú

'I saw the child who I/ stole a book from.'

ni-m-weené/ mw-ana w-aa mi/ni-m-bozelo chi-buukú

'I saw/ the child who I/ stole a book from.'

Nuuru/inenzeze gari ya Haají/uziló ${ }^{3}$

'Nuuru/ drove the truck that Haaji/ bought.'

\subsection{Differences in Phrasing Between Relative VP and Non-Relative VP}

At first blush, a relative verb phrase seems to phrase in much the same fashion as a main-clause verb phrase. In particular, Align-XP Right separates postverbal XP's from one another, while not separating the relative verb from its first complement. However, differences do emerge. In the following sections we discuss the main differences that we have so far observed.

\subsubsection{Postposed subjects}

Postposing of subjects in main clauses is usually possible, but postposed subjects typically do not phrase with a preceding verb in active clauses.

(21) fiile/Muusa tulushile/ mu-nthu oyo tezeeze/ Muusa n-jiilé/ mi
'Died/ Muusa.' (*file Muusa)

'Fell/ that man.' (*tulushile mu-nthu oyo) 'Played, danced/ Muusa.' ( “tezeze Muusa) 'Ate/ I.' ('njilee mí.)

Notice that an object prefix referring to the head may appear on the relative verb.

3 The final accent on Haaji in this example has been noted only in recent work. Further research is required to determine its use as opposed to inenzeze gari ya Haaji, which is the sort of pronunciation we generally recorded in our earlier work with MI. 
The ill-formed sentences that would result from grouping the postposed subject with the preceding verb in the above examples is shown by the examples marked with an asterisk. The reader is reminded that the difference in pronunciation between tulushile/ mu-nthu oyo and *tulushile mu-nthu oyo is that in the former case there is an accent ( $\mathrm{H}$ tone) on the penult syllable of tulushile while in the latter case there is no accent at all. It cannot be stressed too much: only the last vowel of a phrase bears an accent and it always bears an accent. No word that is not final in the phrase ever bears accent. The phrasing thus tells us directly whether a word is accented or not. With regard to accent location, that is contrastive only when the phrase ends in a word with two or more syllables. As discussed earlier, in that situation, we indicate only the marked case where accent is final. In the absence of a final accent, default penult accent occurs.

It would be incorrect to say that a postposed subject never phrases with the verb. A rather common case is in passive sentences where a non-subject NP is fronted and the subject of the passive verb postposed after the verb. We give examples in (22a). (It should be noted that the passive extension oow in Chimwiini is superficially missing in the perfect tense used in the examples below; it does, however, have two notable effects: it induces a change of a preceding alveolar $\boldsymbol{l}$ to a dental $\underline{\boldsymbol{l}}$, and it requires the final vowel $\boldsymbol{a}$ instead of the usual $\boldsymbol{e}$ that occurs in the perfect tense.) In addition to the case of passive verbs, we can find examples like those in (22b) where it appears that the postposing is rendered acceptable by the subsequent clausal unit. More research is necessary into these instances where a postposed subject is grouped with the verb.

(a) examples from passive sentences: ${ }^{4}$

chi-buuku/pela mw-aana/ na mw-aalimu

'Book/ was given the child/ by the teacher.'

=mw-aana/pela chi-buuku/na mw-aalimu.

'The child/ was given a book/ by the teacher.'

\section{Ch-aakuja/pikililia Jaama/na Hamadi.}

'Food/ was cooked-for Jaama/ by Hamadi.'

=Jaama/pikililila ch-aakuja/ na Hamadi.

'Jaama/ was cooked-for food/ by Hamadi'

Wa-tumila ma-'askari/xfitisha nuumba.

'Was sent policemen/ to search the house.'

4 In both of the first two sentences in this data set, $\boldsymbol{m} \boldsymbol{w}$-aana is subject of the sentence and controls subject agreement on the verb peela, though in this case the agreement is phonologically null. 
=Ma-'askari/wa-tumila $x$-fitisha nuumba.

'Policemen/ were sent to search the house.'

(b) examples from non-passive sentences:

lizile Haliima/mpaka/maa-țo/ya-m-furiile

'Cried Haliima/ until/ (her) eyes/ swelled'

file Muusa/ Nuuru/oloshele

'(As soon as) died Musa/ Nuuru/ left.'

tulushile mu-nthu oyo/ ta-ku-yaawata

'(The way) fell man that/ will shock you'

When we turn to relative clauses, postposed subjects do occur, but when they occur in post-verbal position, they are typically phrased with the verb. Moreover, they always occur within the scope of the final accent shown by relative verbs, whether they occur immediately after the verb or later. When the subject is postposed, the head of the object relative clause is located directly in front of the relative verb and there is no $\boldsymbol{A} \boldsymbol{G R} \boldsymbol{R} \boldsymbol{a}$ link since there is no subject for the $\boldsymbol{A G R}-\boldsymbol{a}$ to join together with.

(a) fatuura/y-a Nuuru/ta-k-uuló fatura y-a Nuuru/ta-k-uuló fatuura/ ta-k-ulo Nuurú fatura ta-k-ulo Nuurú

$$
\begin{aligned}
& \text { 'the car/ that Nuuru/ will buy' } \\
& \text { 'the car that Nuuru/ will buy' } \\
& \text { 'the car/ (that) will buy Nuuru' } \\
& \text { 'the car (that) will buy Nuuru' }
\end{aligned}
$$

(b) gaari/pakizo Nuurú/ma-jiwé

'the truck/ that was loaded (i.e. by) Nuuru/ with stones'

gaari/uzilo Haaji/s-paandi

'The truck/ that bought Haaji/ I will not ride (in it).'

Nuuru/inenzeze gaari/uzilo Haají

'Nuuru/ drove the truck/ (that) bought Haaji.'

(c) zi-buuku/bozelo mw-iizí/nz-aaká

'The books/ (that) stole the thief/ are mine.'

zi-buku bozelo mw-iizí/nz-aaká

'The books (that) stole the thief/ are mine.' 
(d) fațura/inenzezo Nuurú/ killa muunthí/ng-

'The car/ (that) drove Nuuru/ each day/ is mine.'

fatura inenzezo Nuurú/ killa muunthí/ nd

'The car (that) drove Nuuru/ each day/ is mine.'

fatuura/inenzezo kila muu-nthí/ Nuurú/nd-aaká

'the car/ (that) drove each day/ Nuuru/ is mine.'

(e) zi-jo/pishilo Faatimá/ mi/speendi

'The food/ cooked Faatima/ I/ do not like it.'

pesa bozelo mw-iizí/s-taali

'The money stole the thief/ I won't take it.'

(f) n-guwo/fuzilo Faatimá/nz-aaká

'The clothes/ washed Faatima/ are mine.'

n-guwo fuzilo Faatimá/ nz-aaká

'The clothes washed Faatima/ are mine.'

cf. n-guwo z-a Faatima/fuziló/n-zaaká

'The clothes that Faatima/ washed/ are mine.'

The data in (23) illustrates a number of points. The fact that the postposing of the subject leads to the absence of the $\boldsymbol{A G R} \boldsymbol{\boldsymbol { a }} \boldsymbol{a}$ link can be seen from comparing n-guwo z-a Faatima/ fuziló/ nz-aaká 'the clothes that Faatima/ washed/ are mine' and n-guwo fuzilo Faatimá/ nz-aaká 'the clothes washed Faatima/ are mine.' When the head is adjacent to the relative verb, it is possible to separate it phrasally, as in $\boldsymbol{n - g u w o / f u z i l o ~ F a a t i m a ́ / n z - a a k a ́ , ~ b u t ~ i t ~ i s ~ a l s o ~ p o s s i b l e ~ t o ~ j o i n ~ i t ~}$ into the same phrase as the verb: $\boldsymbol{n}$-guwo fuzilo Faatimá/nz-aaká.

The postposed subject, if located immediately after the verb, is (typically) in the same phrase as the verb and thus in the scope of the final accent of the verb. It is possible, however, for the postposed subject to follow a complement

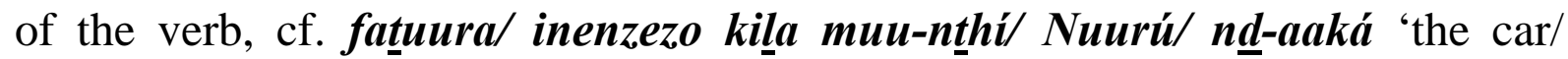
(that) drove each day/ Nuuru/ is mine.' What we see from this example is that the postposed subject is still within the scope of the final accent on the relative verb.

\subsubsection{Negative verbs}

As we discussed earlier, the default case is that a main clause negative verb is separated phrasally from any following complement. (24) provides examples: 
(24) marti $w$-iitu/ile numbaa=ni

'Our guest/ went home.' vs. marti w-iitu/nth-aa-ku-ya/numbaa $=n i$

'Our guest/ did not go/ home.'

mu-kee $=w-e /$ shishile miimba

'His wife/ became pregnant.' vs.

mu-kee=w-e/nth-a-x-shiika/miimba

'His wife/ did not become/ pregnant.'

uyu/ta-k-infa kaazi

'This one/ is suitable for the job.' vs.

uyu/h-a-ta-k-iinfa/ kaazi

'This one/ is not suitable/ for the job.'

In relative clauses, however, the negative verb does not typically stand at the end of a phrase:

(25) ha-fundowi na maama=y-é/ hu-m-fundo l-mweengú

'The one who is not taught by his mother/ is the one whom the world teaches.' (A proverb.)

muu-nthu/nth-a-x-tindaa namá 'the man/ who did not cut meat' variations: mu-nthu oyo/nth-a-x-tindaa namá

(oyo is a demonstrative element)

\section{mu-nthu nth-a-x-tindaa namá}

mu-nthu oyo nth-a-x-tind $\underline{\text { aa }}$ namá

mu-nthu ha-ta-x-fanya kaazí 'the man who won't work'

(cf. ha-ta-x-faanya/ kaazi 'He won't do/ work.')

mu-ke (/) nth-a-m-fulila mw-aaná/ n-guwó/ ni Haliima

'The woman(/) who did not wash for the child/ clothes/ is Haliima.'

(cf. Haliima/nth-a-m-fulila/mw-aana/n-guwo

'Haliima/ did not wash for/ the child/ clothes.')

The explanation for the failure of the negative verb in a relative clause to be at the end of a phrase seems to be this: in the default case, a relative verb phrase lacks internal focus. This principle is apparently stronger than the principle that a negative verb is focused in the default case.

In the following data set, we combine the issue of negative phrasing in relative clauses with subject postposing: 


\section{n-guwo z-a Haliima/nth-a-x-fulá/nz-aaká}

'The clothes that Haliima/ did not wash/ are mine' n-guwo nth-a-x-fula Haliimá/ nz-aaká

'The clothes (that) did not wash Haliima/ are mine.'

What we see from (26) is that a postposed subject is joined with a negative verb into the same phrase. This example supports the general proposition that a negative verb in a relative clause behaves in a fashion just like an affirmative verb, whereas the two are quite distinct in their main clause behavior.

\subsubsection{Time Adverbials in Relative Clauses}

As we discussed earlier, in main clause verb phrases, time adverbials typically are separated phrasally from the preceding verb and are always separated from a preceding XP in a fashion that is made obvious in the case of the final-accent triggered by person. In relative clauses, time adverbials always fall within the scope of the final accent and also join into a phrase with an immediately preceding verb.

\section{(27) mw-aana/bashizo chi-buukú/yuuzí}

'the child/ who lost the book/ yesterday' mw-ana oyo/bashiizó/ chi-buukú/yuuzí

'that child/ who lost/ the book/ the day before yesterday'

Musa nth-a-na-ku-ja isá 'the Muusa who is eating now'

mw-iizi/oyo/shishilaa yaná 'thief/ that one/ who was caught yesterday'

mw-iizi/shishila na ma-poliiisí/yaná

'the thief/ who was caught by the police/ yesterday'

mu-nthu na-x-safira leeló/ ni Nuuru

'The person who is leaving on a trip today/ is Nuuru.'

mw-anaamke/pishiloo namá/ yaná/ ni Haliima

'The girl/ who cooked meat/ yesterday/ is Haliima'

An example like $\boldsymbol{m} \boldsymbol{w}$-iizi/ oyo/ shishilaa yaná shows that the time adverbial is not separated from the verb inside a relative clause. An example like $\boldsymbol{m} \boldsymbol{w}$-iizi/ shishila na mapoliisí/ yaná shows that the time adverbial falls within the scope of the final accent of the relative verb. Both of these behaviors separate time adverbials in relative clauses from time adverbials in main clause.

\subsubsection{The Accentual Law of Focus and Relative Clauses}

In this section we consider the issue of whether the Accentual Law of Focus is applicable to relative clauses. The issue is rendered somewhat difficult by the 
fact that in the usual case, relative clauses do not exhibit phrasing that indicates the presence of a focused element inside the relative verb phrase. In our work with Mohammad Imam Abasheikh, we almost never encountered such sentences in our elicitation sessions. There are, however, occasional examples in our text collection that suggest that it might be possible to have some sort of internal focus. Consider, for instance, the following examples:

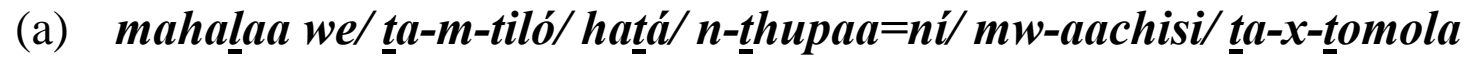
ch-aala

'The place where you/ put him/ even though/ (is) in a bottle/ a bastard/ will stick out his finger (showing he is there).' (A proverb.)

(b) Sku mooyi/ mw-anaamke/ naayé/ kaleențó/ nthi/ naxsuko msalá... ${ }^{5}$

'One day/ the girl/ while she/ was sitting/ on the floor/ knitting a mat...'

(c) Tawalishiizo=pó/ u-sultaaní/mw-aana/chi-m-vila waziiri/m-kulu.

'When he was installed/ as king/ the boy/ called the minister/ chief.'

(d) Fungaa=ni/ safari/ endaa=ni/ karkaa nthi/ mbili/ huyo ba'ada ya nthi yiitú/ iýr.

'You (plural) set off/ on a journey/ and go/ to the lands/ two/ which come after our land/ this'

In each of these examples what we see is that the final accent associated with the relative clause extends to the end of the relative clause even if there is a focused element that occurs at the end of a phonological phrase not predicted by AlignXP Right.

In our elicitation sessions with Jeylaani Mohamed Diini, it is clear that his first preference is that there be no internal focus inside the relative clause. Thus in the optimal case, the relative verb should be grouped with the immediately following complement and should not stand at the end of a phonological phrase unless it is also the end of the verb phrase. However, Jeylaani accepts focus on the verb, but in that case prefers that the final accent associated with the relative continue past the focused verb to the end of the relative clause. Pronunciations where the accent obeys the Accentual Law of Focus and stops at the focused word were considered of dubious validity. (29) illustrates:

5 This is an example of an adverbial relative clause, a type of relative we have omitted from discussion for the most part in this paper, but it still indicates the possibility of internal focus in a relative clause. (28c) provides another example from the domain of adverbial relative clauses, which appear more extensively in texts than do ordinary relative clauses. (28d) comes from an ordinary relative clause, but the internal focus involved is one that sets off the demonstrative element $\boldsymbol{i} \boldsymbol{y} \boldsymbol{i}$ from the phrase $\boldsymbol{n} \underline{\underline{t}} \boldsymbol{h} \boldsymbol{i} \boldsymbol{y i i t u}$ 'our land'. 
(29)

(a) mw-aana/bashizo chi-buukú 'the child/ who lost the book' variants: mw-ana oyo/bashizo chi-buukú mw-ana bashizo chi-buukú mw-ana oyo bashizo chi-buukú

but also:

mw-ana oyo/bashiizó/ chi-buukú 'that child/ who lost/ the book'

(b) mu-ke (/) nth-a-m-fuliliá/mw-aaná/n-guwó/ni Haliima

'The woman (/) who did not wash for/ the child/ clothes/ is Haliima.'

cf. (with final accent stopping at the verb)

*mu-ke nth-a-m-fulilál/mw-aana/n-guwo/ni Haliima

'The woman who did not wash for/ the child/ clothes/ is Haliima.'

(c) mu-nthu nth-a-x-tindaa namá/ 'the man who did not cut the meat' (best version)

mu-nthu nth-a-x-tiindá/namá/ 'the man who did not cut/ the meat' (acceptable version)

cf.

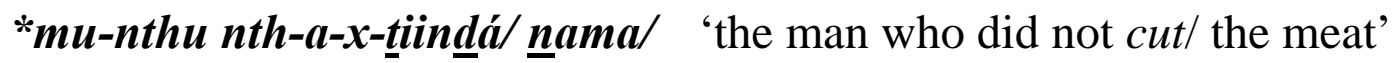
(dubious version, where final accent stops at the verb)

(d) mw-aana/uziizó/ chi-buukú 'the child/ who sold / book' muu-nthu/m-weenó/mw-iizí 'the man/ who saw/thief' mw-aana/naa=ch-ó/ chi-buukú 'the child/ who has/ the book'

(e) n-guwo fuziló/ Faatimá/nz-aaká 'The clothes washed/ Faatima/ are mine.' (with subject postposing)

*n-guwo fuziló/ Faatima/nz-aaká

'The clothes washed/ Faatima/ are mine.'

(with final accent not passing the verb)

(f) fațura/inenzeezó/ Nuurú/ killa muu-nthí/nód-aaká 'the car/ that drove/ Nuuru/ each day/ is mine'

What these data suggest is that even when there is focus internal to the relative clause, the final accent extends to the end of the relative VP. This in turn indicates that the Accentual Law of Focus does not apply to the relative clause.

\section{Pseudo-Relative Clauses}

There are a variety of sentential types where a main verb is put into a relative form. We call these relative verb forms pseudo-relatives. In some cases of 
pseudo-relativization, the main verb of the sentence may be considered to be the copular $\boldsymbol{n i}$. The sentences with $\boldsymbol{n i}$ may, however, appear with the $\boldsymbol{n i}$ omitted. Since it is not unusual for $\boldsymbol{n} \boldsymbol{i}$ to be elided even in simple copular expressions, one might continue to regard the relative verb clauses in these sentences to be embedded rather than main verbs. However, in some cases of pseudorelativization, it is not possible for the copular to be used and in these cases it is less evident that the pseudo-relative verb is not the main clause of the sentence. In any case, we shall explore the phrasing of pseudo-relative verbs and consider their connection to main clause verbs as well as true relative clauses.

\subsection{Cleft Structures}

Cleft sentences of the form $\boldsymbol{n i} \boldsymbol{X P}$ - (YP) - (relative) verb phrase provide a typical example of the pseudo-relative. Look at the examples in (30). The final accent on the verb phrase is the most consistent indication that the verb is treated as a relative. In addition, the verb ends in the vowel $\boldsymbol{o}$ in affirmative finite active tenses.

(30) ni Muusa/ koteeló

'It is Muusa/ who spoke.'

ni Muusa/nth-a-x-kootá

'It is Muusa/ who did not speak.'

ni Muusa/ kotelo ka l-kelé

'It is Muusa/ who spoke loudly.'

ni Muusa/nth-a-x-kota ka l-kelé

'It is Muusa/ who did not speak loudly.'

ni Muusa/ hu-pendo n-tholokó

'It is Muusa/ who likes beans.'

ni chi-buuku/ch-uziizá

'It is a book/ that was sold.'

ni Muusa/na=y-o chi-buukú

'It is Muusa/ who has a book.'

ni Muusa/lumila naa noká

'It is Muusa/ who was bitten by a snake.'

ni Nuuru/bozelo chi-buukú

'It is Nuuru/ who stole book.'

ni waawa $=y$-e/m-loweezó

'It is his father/ who financed his wedding.'

ni Muusa/wa-pelo w-aaná/maandá

'It is Muusa/ who gave the children/ bread.'

ni w-aana/Muusa/wa-pelo maandá

'It is the children/ whom Muusa/ gave bread.' 
ni ch-olokoo=ni/Suufi/ latililo i-jiwé

'It is at a window/ that Suufi/ threw a stone.'

Each of the examples in (30) involves locating a subject or a complement NP at the beginning of a sentence, preceded by the copular $\boldsymbol{n i}$, and then casting the verb in a relative form (i.e. with the final vowel $\boldsymbol{o}$ in a range of cases and a final accent that extends to the end of the verb phrase).

In our data, the $\boldsymbol{n i}$ precedes the first phrase in the sentence, but not a subsequent phrase:

(31) ni zi-buku z-iingi/mw-aalimu/someeló

'It is many books/ that the teacher/ has read.'

ni z-iingi/zi-buuku/mw-aalimu/someeló

'They are many/ the books/ that the teacher/ has read.'

*z-iingi/ni zi-buuku/mw-aalimu/someeló

'Many/ it is the books/ that the teacher/ has read.'

ni w-aana/Muusa/wa-pelo maandá

'It is the children/ that Muusa/ gave bread.'

*w-aana/ni Muusa/wa-pelo maandá

'The children/ it is Muusa/ who gave them bread.'

The NP preceded by the copular $\boldsymbol{n i}$ is typically emphasized, which means that the pitch height is abnormally raised. We have not indicated this aspect of the pronunciation here.

\subsection{Questions and Pseudo-Relativization}

In the preceding section we looked at overt cleft structures. There are, however, various types of sentences which are like cleft sentences in that the verb is converted into relative form, but the $\boldsymbol{n i}$ is absent, or at least may be absent. One of the cases where the $\boldsymbol{n i}$ is commonly absent is in the equivalent of English $\boldsymbol{w h}$ questions. We will illustrate with the question word naani 'who(m)?' and gani 'which?'.

When question words precede the verb, the verb is put into pseudo-relative form. (Notice that there is no pseudo-relativization of the verb when naani or gani is post-verbal):

naani/ koteeló
naani/pishiló
naani/kotelo ka l-kelé
naani/nth-a-x-kootá
chi-buku ch-a naani/peetó
naani/ uzilo chi-buukú

'Who/ spoke?'

'Who/ cooked?'

'Who/ spoke loudly?'

'Who/ did not speak loudly?'

'Whose book/ did you find?'

'Who/ bought the book?' 


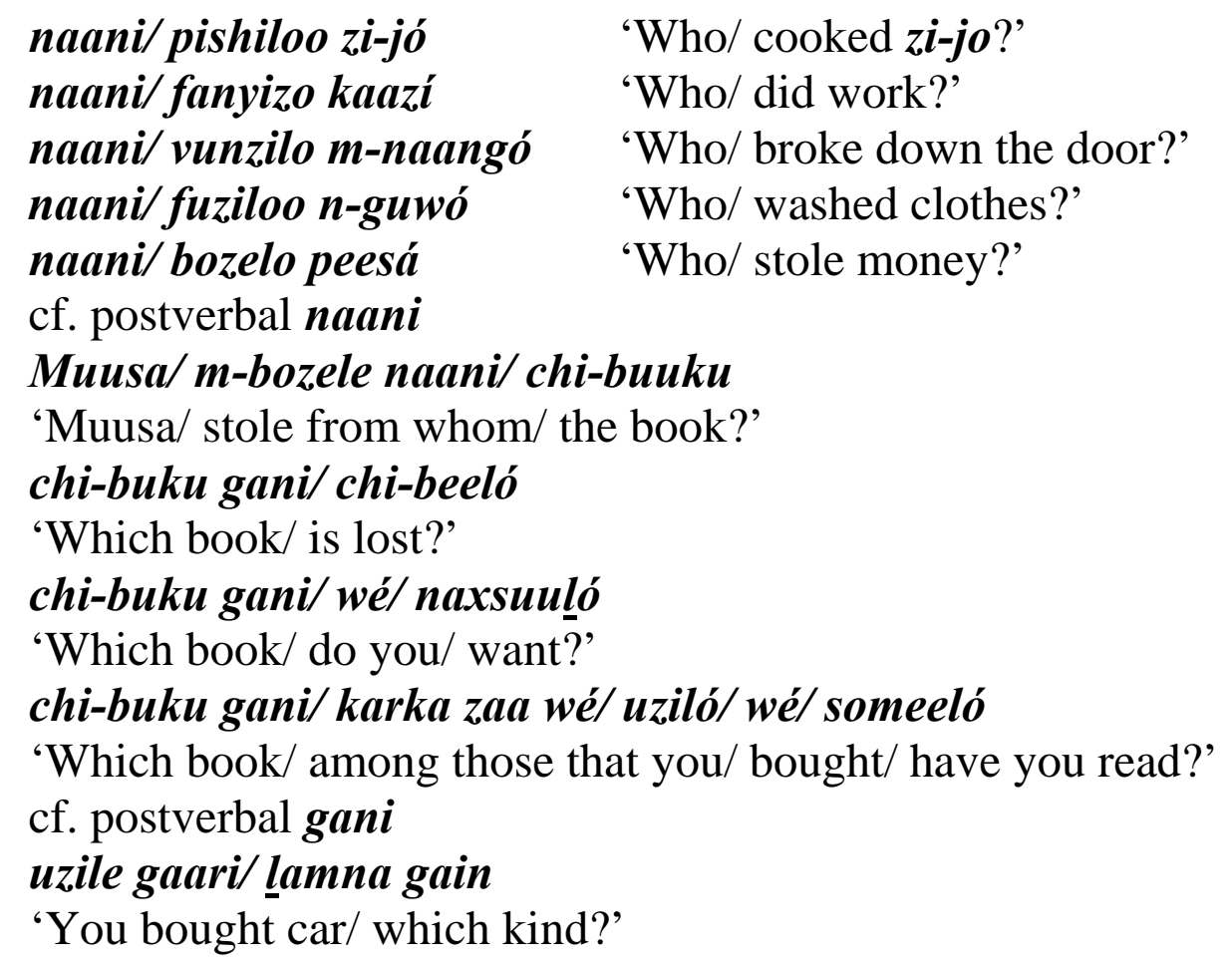

Questions may also have an overt cleft structure - ni naani/ kođeeló 'it is who that spoke?' - but these were not the forms first offered by our consultants. The accent on the question word in the above example is higher than in the case of a non-question word, but we have not indicated this pitch raising.

\subsection{Pseudo-Relativization Triggered by Various Pre-verbal Elements}

There are many other elements in addition to question words which, when located in pre-verbal position, trigger pseudo-relativization. A few pre-verbal triggers are illustrated here. We should stress that these examples of pseudorelativization are frequent in the data recently collected, but not in the data collected from Mohammad Imam Abasheikh in the 1970's and 1980's. The trigger in these examples most likely can be preceded by the copular $\boldsymbol{n i}$, but they generally were volunteered without the copula being present.

Note that the symbol " is used to indicate raised pitch on a subject noun that has been emphasized and triggers pseudo-relativization. We have not used this symbol when the subject is preceded by $\boldsymbol{n i}$ or when the subject is a question word or when it is a non-subject element that triggers pseudo-relativization.

(a) emphasized subject
"Muusa/ kodeeló
(cf. Muusa/ koteele 'Muusa/ spoke.')
'(It is) Muusa/ who spoke.' 
"Nuuru/fiiló

'(It is) Nuuru/ (who) died.'

(cf. Nuuru/ fiile 'Nuuru/died.')

"Haliima/ uzilo chi-buukú ' (It is) Haliima/ (who) bought the book.'

(cf. Haliima/ uzile chi-buuku 'Haliima/ bought the book.')

"Muusa/someloo ch-iwó 'Muusa/ (is the one) who read the book'

(cf. Muusa/ somele ch-iwo 'Muusa/ read the book.')

"mw-aana/uzizo chi-buuku' 'The child/ (is the one) who sold the book'

(cf. mw-aana/uzize chi-buuku 'The child/ read the book.')

"Nuuru/bozelo chi-buukú '(It is) Nuuru/ who stole the book.'

(cf. Nuuru/bozele chi-buuku 'Nuuru/ stole the book.')

(b) $\underline{t} \boldsymbol{u}$-marked NP

zi-buuku/tu/Haliima/ uziló 'Books/ only/ Haliima/ bought.'

Haliima/zi-buuku/t u/ uziló 'Haliima/ books/ only/ bought.'

w-aana/tu/Haliima/wa-'ulilio zi-buukú

'Children/ only/ Haliima/ bought for them books.'

zi-buuku/tu/Haliima/wa-'ulilo w-aaná

'books/ only/ Haliima/ bought for the children.'

Haliima/tu/ uzilo chi-buukú 'Haliima/ only/ bought a book.'

(cf. Haliima/ uzile chi-buuku 'Haliima/ bought a book.')

cf.

Haliima/ uzile zi-buuku/t $\boldsymbol{u}$ ' 'Haliima/ bought books/ only.'

(post-verbally, $\underline{\boldsymbol{t}} \boldsymbol{u}$ does not trigger pseudo-relativization)

Haliima/ tu/wa-'ulilo w-aaná/zi-buukú

'Haliima/ only/ bought for the children/ books.'

(cf. Haliima/wa-'ulile w-aana/zi-buuku

'Haliima/ bought for the children/ books'

cf. post-verbal $\underline{\underline{t}} \boldsymbol{u}$ does not trigger pseudo-relativization

Haliima/wa-'ulilie w-aana/ tu/zi-buuku

'Haliima/ bought for the children/ only/ books.'

Haliima/wa-'ulilie w-aana/zi-buuku/tu

'Haliima/ bought for the children/ books/ only.'

(c) Muusa/ tú/na-x-sulo mw-aaná/ ku-já 'Muusa/ only/ wants child/ to eat.'

(cf. Muusa/ na-x-sula m-aana/ $\boldsymbol{k}$ u-ja 'Muusa/ wants child/ to eat.')

(d) preposed complement $\mathrm{NP}$

"Muusa/chi-buuku=ch-e/ m-pheetó 'Muusa/ his book/ I found.'

"chi-buku ch-a Muusa/m-pheetó 'Muusa's book/ I found (it).'

"maayi/ Muusa/leeseló

"w-aana/Muusa/wa-pelo maandá

'The children/ Muusa/ gave them bread.' 


\subsection{Pseudo-Relativization Lacking a Cleft Variant}

We have seen that various pre-verbal elements trigger pseudo-relativization. The issue here is whether in such cases we are always dealing with reduction of a cleft construction, i.e. do all cases of pseudo-relativization involve an underlying copular $\boldsymbol{n i}$ that has been (optionally) omitted? Some insight into this question may be gotten from considering verb tenses that (a) do not appear in ordinary relative clauses and (b) are not compatible with the cleft structure, i.e. cannot employ the copular $\boldsymbol{n i}$ when used in a pseudo-relative. Consider the imperative verb data below:

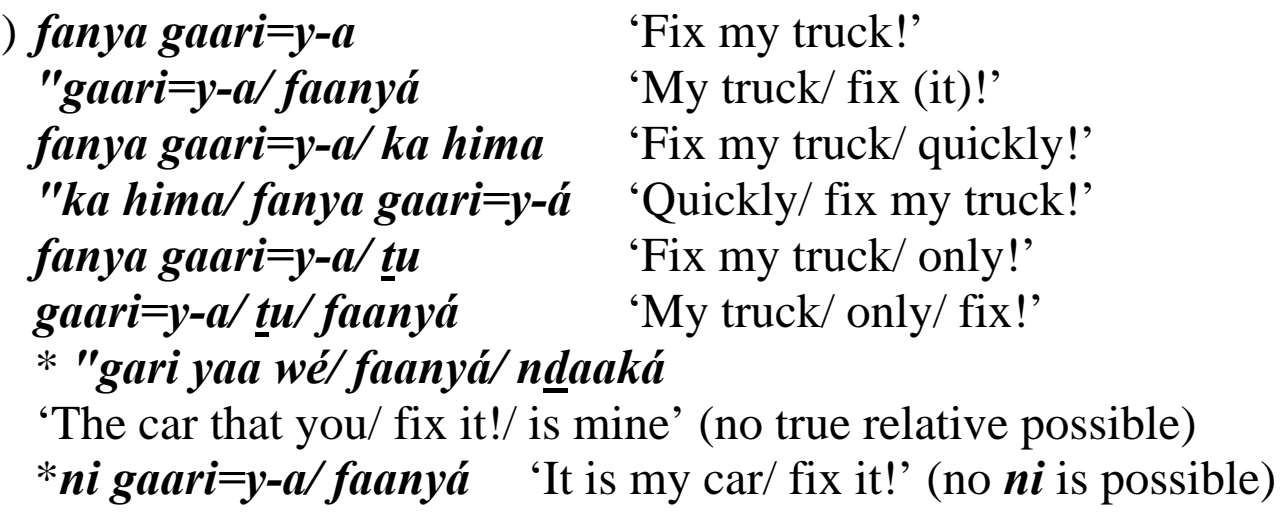

The data in (34) show that, in the absence of a pre-verbal element, an imperative verb phrase has default penult accent: fanya gaari=y-a, fanya gaari=y-a/ $\boldsymbol{k a}$ hima, fanya gaari=y-a/t $u$. If the object is moved to initial position, as in "gaari=y-a/faanyá or gaari=y-a/ tu/faanyá, then the imperative verb phrase displays final accent. This makes sense if we assume that the verb is being put into a pseudo-relative form. If an adverbial element is put into initial position, as in $\boldsymbol{k a}$ hima/ fanya gaari=y-á, we also see the verb phrase shift to final accent. Finally, it is significant that an imperative verb does not seem to ever appear in an ordinary relative clause. Furthermore, the preposed element that triggers pseudo-relativization may not be preceded by the copular ni. We seem, therefore, to have a situation where the pseudo-relative is transparently independent of the copular.

Another class of examples making the same point is the subjunctive verb:

(35) Muusa/na-'oloke

"Muusa/na-'oloké

*ni Muusa/na-'oloké

Muusa/ tu/na-'oloké
'Let Muusa/ go.'

'It is Muusa/ that should go.'

(no overt $\boldsymbol{n i}$ is possible in this example)

'Muusa/ only/ should go.' 


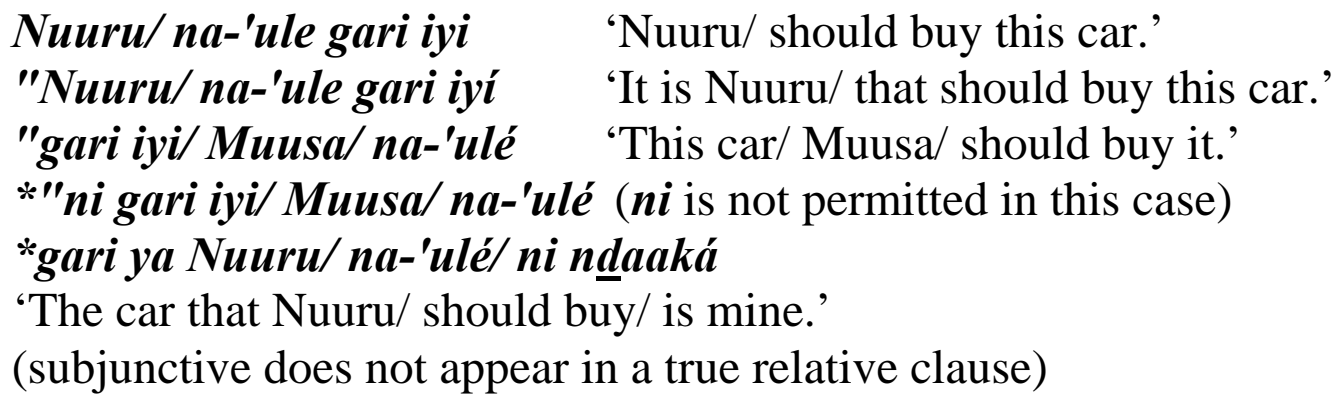

The data in (35) show that a subjunctive verb is just like an imperative verb in that it is cast into a pseudo-relative form when there is a pre-verbal trigger, even though subjunctives neither appear in true relatives nor are they compatible with a copular $\boldsymbol{n i}$ in front of the trigger. We conclude, therefore, that pseudorelativization does not necessarily involve a cleft structure.

\subsection{Phrasing of Pseudo-Relatives}

In this section we look at the phrasing of the pseudo-relative verb. It should be pointed out immediately that no XP in front of the pseudo-relative verb groups together with that verb into the same phonological phrase. Thus we can only say gaari=y-a/faanyá 'my truck/ fix (it)!' and never *gari=y-a faanyá. Given this fact, then we are concerned only with the issue of the phrasing and accentual properties inside the pseudo-relative verb phrase. In particular, is the phrasing like main clause verb phrases or like ordinary relative clauses? We explore this question in the subsections below, but the data are not entirely clear cut at present. More research is required.

\subsubsection{Postposed Subjects and Pseudo-Relativization}

Consider first the matter of postposed subjects. In main clauses, a postposed subject ordinarily does not join with the verb into a single phrase. In ordinary relative clauses, on the other hand, a postposed subject does join with the relative verb into a single phrase and is within the scope of the final accent that the relative verb triggers. Our consultant rejected including a postposed subject in the same phrase as a pseudo-relative verb and also rejected including the postposed subject in the scope of the final accent of the pseudo-relative verb. (36) illustrates these points:

(a) fatuura/takuuló/ Nuuru '(It is) a car/ that bought/ Nuuru.' *fatuura/ țakulo Nuurú (no joining of postposed subject to the pseudo-relative verb) *fatuura/ takuuló/ Nuurú (no extension of final accent to the postposed subject) 
(b) zi-jo/pishiló/ Faatima '(It is) the $\boldsymbol{z} \boldsymbol{i}$-jo/ cooked/ Faatima.'

*zi-jo/ pishilo Faatimá

(no joining of postposed subject to the pseudo-relative verb)

*zi-jo/pishiló/ Faatimá

(no extension of final accent to the postposed subject)

cf.

zi-jo/pishile/Faatima 'The food/ cooked/ Faatima.'

(main clause postposing)

${ }^{*}$ zi-jo/pishile Faatima

(no joining of postposed subject to the main clause verb)

(c) peesa/boozeló/maskiini '(It is) the money/ that stole/ the poor man.'

*peesa/ bozelo maskiiní

(no joining of postposed subject to the pseudo-relative verb)

*peesa/ boozeló/ maskiiní

(no extension of final accent to the postposed subject)

cf.

peesa/boozele/maskiini 'Money/ stole/ the poor man.'

(main clause postposing)

*peesa/ bozele maskiini

(no joining of postposed subject to the main clause verb)

(d) m-naango/vuunziló/ $\boldsymbol{m} \boldsymbol{w}$-iizi '(It is) the door/ broke/ the thief.'

*m-naango/vunzilo mw-iizí

(no joining of postposed subject to the pseudo-relative verb)

*m-naango/vuunziló/ mw-iizí

(no extension of final accent to the postposed subject)

cf.

m-naango/vuunzile/ $\boldsymbol{m} \boldsymbol{w}$-iizi 'The door/ broke down/ the thief.'

(main clause postposing)

*m-naango/vunzile mw-iizi

(no joining of postposed subject to the main clause verb)

(e) $\boldsymbol{k a a}$ n-khele/ anziizó/Muusa/ $\boldsymbol{k u}$-ḷa 'Loudly/ began/ Muusa/ to cry.'

kaa n-khele/ anzizoo ku-liá/ Muusa 'Loudly/ began to cry/ Muusa.'

*kaa n-khele/ anzizo Muusá/ ku-láá

(no joining of postposed subject to the pseudo-relative verb)

*kaa n-khele/ anzizo ku-liá/ Muusá

(no extension of final accent to the postposed subject)

These examples contrast with the case of a true relative clause, where the postposed subject may be phrased with the relative verb and in any case falls 
within the scope of the final accent. In pseudo-relativization, the postposing facts (with regard to phrasing and accent scope) parallel main clauses.

\subsubsection{Negative Verbs and Pseudo-Relativization}

Recall that in the case of negative verbs, the default phrasing is for the negative verb to be at the end of a phonological phrase. We assume that there is an inherent focus on the negative verb. Muusa/ haapiki/ maanda 'Muusa/ does not cook / bread'. However, it is possible to include the complement in the phrase with the negative verb when the complement is being focused: Muusa/ hapiki maanda 'Muusa/ does not cook bread'. However, this clearly represents a phrasing that is out of the ordinary. In true relative clauses, the negative verb typically is not separated from its complement and certainly is within the scope of the final accent of the negative verb. In the case of pseudo-relativization, the negative verb may or may not be at the end of the phonological phrase. However, the data below indicates that the Accentual Law of Focus is obeyed (but more research is required due to the fact that there is some uncertainty in our data on this point):

(37) naani/ nth-a-m-wona Omarí 'Who/ did not see Omari?' naani/ nth-a-m-woná/ Omari 'Who/ did not see/ Omari?' (apparently, the Accentual Law of Focus is enforced)

*naani/nth-a-m-woná/ Omarí 'Who/ did not see/ Omari?' (unacceptable because of the Accentual Law of Focus violated) cf. Nuuru/nth-a-m-wona/ Omari 'Nuuru/ did not see/ Omari.' (canonical main clause phrasing)

(ni) Muusa/ hapiki maandá (ni) Muusa/ haapikí/ maanda (Accentual Law of Focus obeyed) *(ni) Muusa/ haapikí/ maandá (Accentual Law of Focus violated) cf.

Muusa/haapiki/maanda (main clause canonical phrasing)

\section{Muusa/ tu/ha-ji m-bogá}

Muusa/ tu/ haa-jí/m-boga
'(It is) Muusa/ (who) did not cook bread.' '(It is) Muusa/ (who) did not cook bread.'
'Muusa/ did not cook/ bread.'
'Muusa/ only/ does not eat greens.'

'Muusa/ only/ does not eat/ greens.' (this pronunciation obeys Accentual Law of Focus)

*Muusa/ tu/haa-jí/m-boga

(this pronunciation would violate Accentual Law of Focus) cf.

Muusa/haa-ji/m-boga

(main clause canonical phrasing) 
naani/nth-a-m-pá/ Omari/peesa 'Who/ did not give/ Omari/ money?' (Accentual Law of Focus obeyed)

naani/nth-a-m-pa Omarí/peesá 'Who/ did not give Omari/ money?' (Accentual Law of Focus obeyed since there is no VP-internal focus) *naani/nth-a-m-pá/ Omarí/pees 'Who/ did not give/ Omari/ money?' (Accentual Law of Focus violated) cf.

Nuuru/nth-a-m-pa/Omari/peesa 'Nuuru/ did not give/ Omari/ money.' (main clause canonical phrasing)

The examples above show the variation between whether the negative pseudorelativized verb is phrase-final or not: cf. (ni) Muusa/ hapiki maandá versus (ni) Muusa/ haapiki/ maanda. But when the negative verb is phrase-final, these data show that the final accent of the pseudo-relative verb does not extend through the complement to the verb. In other words, the negative pseudorelative parallels in behavior a main clause negative verb and not a negative true relative verb.

\subsubsection{Time Adverbials and Pseudo-Relativization}

Recall that time adverbials in main clauses do not cohere with a preceding verb and are outside the scope of final accent in the default case, while in true relative clauses time adverbials did not behave differently from any other XP. The data from pseudo-relatives has lacked consistency. The data below in (38) includes two examples where the time adverbial is preceded by a complement to the pseudo-relative verb and the final accent triggered by the verb extends to the time adverbial (just like in true relative clauses). In the third example, the time adverbial is immediately after the verb and groups with, receiving the final accent.

(38) naani/ m-shishilo mw-iizi//yaná 'Who/ caught the thief/ yesterday?'

"Muusa/m-shishilo mw-iizi/yaná

'Muusa/ caught the thief/ yesterday.'

gari iyi/ n-uzilo leeló

'This truck/ I bought today.'

But we have also recorded variation in whether the accent does in fact extend to the time adverbial: 
(39) ni mw-anaamke/pishiloo namá/yana

'It is the girl/ who cooked meat/ yesterday.'

but also:

ni mw-anaamke/pishiloo namá/yaná

'It is the girl/ who cooked meat/ yesterday.'

mw-anaamke/ tú/pishiloo namá/ yana

'The girl/ only/ cooked food/ yesterday.'

but also:

mw-anaamke/ tú/pishiloo namá/ yaná

'The girl/ only/ cooked food/ yesterday.'

naani/pishiloo namá/ yana 'Who/ cooked meat/ yesterday?'

but also:

naani/pishiloo namá/ yaná 'Who/ cooked meat/ yesterday?'

Much more work remains to be done on the behavior of time adverbs in pseudorelative clauses, but the initial evidence does suggest that there is a difference between pseudo-relative verbs and true relative verbs when it comes to time adverbials.

\subsubsection{The Accentual Law of Focus and Pseudo-Relativization}

The Accentual Law of Focus is generally obeyed in our data on pseudorelativization, in contrast to true relativization. There is however considerable room for further investigation to make sure that all cases of pseudorelativization behave the same.

The case of preverbal question words and the Accentual Law of Focus is illustrated in (40):

(40) naani/ fuziloo n-guwó naani/fuziló/ n-guwo

*naani/fuziló/n-guwó

naani/bozelo chi-buukú naani/boozeló/ chi-buuku

"naani/boozeló/chi-buukú

naani/ ta-k-ulo fatuurá

naani/ta-k-uuló/ fatuura

*naani/ ta-k-uuló/fațuurá
'Who/ washed clothes?'

'Who/ washed/ clothes?'

'Who/ washed/ clothes?'

'Who/ stole the book?'

'Who/ stole/ the book?'

'Who/ stole/ the book?'

'Who/ will buy a car?'

'Who/ will buy/ a car?'

'Who/ will buy/ a car?'

cf. the behavior of true relatives: 
muu-nthu/ta-k-ulo fațurá/ ni Hamadi

'The man/ who will buy a car/ is Hamadi.'

muu-nthu/ta-k-uuló/fatuurá/ ni Hamadi

'The man/ who will buy/ a car/ is Hamadi.'

In each of the questions above, the verb may be joined with its complement, in which case the final accent goes to the complement. However, the verb may be separated from its complement, and as a consequence the final accent is restricted to the verb.

Other cases of pseudo-relativization also obey the Accentual Law of Focus.

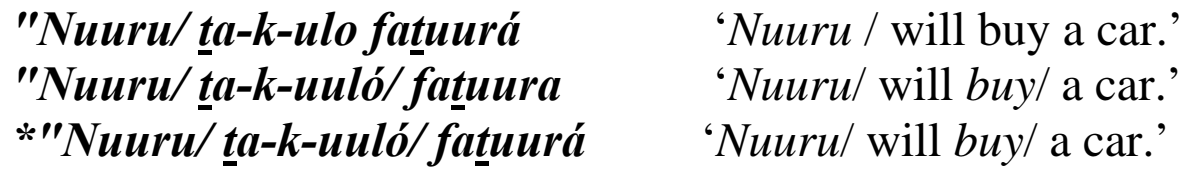

Faatima/ tu/fuziloo n-guwó

'Faatima/ only/ washed clothes.'

Faatima/tu/fuziló/ n-guwo

'Faatima/ only/ washed/ clothes.'

*Faatima/ tu/fuziló/n-guwó

'Faatima/ only/ washed/ clothes.'

muu-nthu/m-weene mw-iizi

muu-nthu/m-weene/ mw-iizi

"muu-nthu/m-weno mw-iizí

"muu-nthu/m-weenó/mw-iizi

*"muu-nthu/m-weenó/mw-iizí

mu-ke/ tinzilee nama

mu-ke/ tiinzíle/ nama

"mu-ke/ tiiinziló/nama

*"mu-ke/ tiiinziló/ namá

(cf. mu-ke/ tiinziló/ namá/ ni m-buja

'The woman/ who cut/ the meat/ is my sister.')

ntho/ kazá

ntho/ kaza musmaarí

ntho/ kazá/ musmaari
'Hard/ drive it in!'

'Hard/ drive in the nail!'

'Hard/ drive in/ the nail!'

ntho/ kaza musmaarí/ n-thunduu=ní

'Hard/ drive the nail/ into the hole!'

ntho/ kazá/ musmaari/n-thunduu=ni

'Hard/ drive/ the nail/ into the hole!'

Omari/shalayete chiza ku-m-pa mw-aana/ peesa. 
'Omari/ regretted not giving the child/ money.'

"Omari/shalayeto chiza ku-m-pa mw-aaná/ peesá.

'Omari/ regretted not giving the child/ money.'

"Omari/shalayeetó/ chiza ku-m-pa mw-aana/peesa.

'Omari/ regretted/ not giving the child/ money.'

Although there is significant evidence that the Accentual Law of Focus restricts the accent in pseudo-relative verbs, we have encountered data that suggest more detailed research is necessary. (42) illustrates this point:

(42) ni naani/ kotelo ka l-kelé 'It is who/ that spoke loudly?'

ni naani/kodeeló/ ka l-kelé ' 'It is who/ that spoke/loudly?'

Muusa/ tu/ koteeló/ ka l-kelée 'Muusa/ only/ spoke/ loudly.'

When the adverb $\boldsymbol{k} \boldsymbol{a} \underline{\boldsymbol{l}} \boldsymbol{k} \boldsymbol{e} \underline{\boldsymbol{e}} \boldsymbol{e}$ groups into a phrase with the pseudo-relative verb, it displays the final accent as expected. When the pseudo-relative verb is separated prosodically from the adverb, we see that, contrary to the Accentual Law of Focus, the final accent extends to the adverb. This behavior appears to contrast with the behavior of the complements in (41). It is not clear at present how to interpret this contrast in our data.

\section{Conclusion}

In this paper we have demonstrated that true relative verb clauses display striking differences with respect to phrasing and the scope of final accent in comparison with non-relative verb phrases. We also noted that there is variation with respect to the phrasing of the heads of true relative clauses. A head located immediately in front of the relative verb may phrase with the verb; this never happens in the case of an XP located in front of a non-relative verb.

There is an extensive use of pseudo-relative clauses in Chimwiini. Pseudorelative clauses show the same morphological use of the final vowel -o and the final accent as in true relative clauses. However, there are significant differences. There is no 'head' of the pseudo-relative verb and thus no variation in the phrasing of this non-existent head. Furthermore, the phrasing and scope of final accent in the pseudo-relative verb phrase is more similar to main clause verb phrases than to true relative clause verb phrases. 


\section{References}

Hyman, L. M. (1999). The interaction between focus and tone in Bantu. In: G. Rebuschi and L. Tuller (eds.). The Grammar of Focus. Amsterdam: John Benjamins, 155-177.

Kanerva, J. M. (1990). Focusing on phonological phrases in Chichewa. In: S. Inkelas and D. Zec (eds.), The Phonology-Syntax Connection. Chicago: University of Chicago Press, 145-161.

Kisseberth, C. W. (2005). Accent and phrasing in Chimwiini. In: S. Kaji (ed.), Proceedings of the Symposium: Cross-linguistic Studies of Tonal Phenomena. Research Institute for Languages and Cultures of Asia and Africa (ILCAA), Tokyo University of Foreign Studies: Tokyo, 129-145.

Kisseberth, C. W. (2010). Optimality Theory and the theory of phonological phrasing: The Chimwiini evidence. In: N. Erteschik-Shir and L. Rochman (eds.), The Sound Patterns of Syntax. Oxford University Press: Oxford and New York, 217-246.

Kisseberth, C. W. \& M. I. Abasheikh (1974). Vowel length in Chi-Mwi:ni - a case study of the role of grammar in phonology. In: A. Bruck, A. Fox \& M.W. La Galy (eds.), Papers from the Parasession on Natural Phonology. Chicago: Chicago Linguistic Society, 193-209.

Kisseberth, C. W.\& M. I. Abasheikh (2004). The Chimwiini Lexicon Exemplified. Asian and African Lexicon no. 45: Research Institute for Languages and Cultures of Asia and Africa (ILCAA), Tokyo University of Foreign Studies. Tokyo.

Selkirk, E. (1986). On derived domains in sentence phonology. Phonology Yearbook 3, 371405.

Selkirk, E. (2000). The interaction of constraints on prosodic phrasing. In: M. Horne (ed.), Prosody: theory and experiment. Dordrecht: Kluwer, 231-262.

Truckenbrodt, H. (1999). On the relationship between syntactic phrases and phonological phrases. Linguistic Inquiry 30:2, 219-255. 